\title{
GLIM criteria for the evaluation of nutrition in palliative care patients, a comparison of MNA-SF and NRS-2002
}

\author{
๑Hasan Öztin1, @İlyas Öztürk², @Burak Oymak³ \\ ${ }^{1}$ Izmir Katip Çelebi University, Atatürk Training and Research Hospital, Department of Internal Medicine, Division of Geriatrics, İzmir, Turkey \\ ${ }^{2}$ Kahramanmaraş Sütçü İmam University, Faculty of Medicine, Department of Internal Medicine, Division of Nephrology, Kahramanmaraş, Turkey \\ ${ }^{3}$ Health Science University, Erzurum Region Education and Research Hospital, Central Laboratory, Erzurum, Turkey
}

Cite this article as: Öztin H, Öztürk İ, Oymak B. GLIM criteria for the evaluation of nutrition in palliative care patients, a comparison of MNA-SF and NRS-2002. J Health Sci Med 2021; 4(4): 488-492.

\begin{abstract}
Aim: A new malnutrition diagnostic criterion called the Global Leadership Initiative on Malnutrition (GLIM) was created by an initiative of the same name as these criteria in 2018. The present study aims to evaluate the differences and superiority of MNA, NRS-2002 screening tests, and GLIM criteria in patients hospitalized in palliative care with a diagnosis of malnutrition.

Material and Method: 148 patients who were hospitalized in palliative care due to clinical malnutrition were included in the study. MNA, NRS-2002, and GLIM screening tests were filled out by dieticians for each patient within the first 48 hours of hospitalization. Within the framework of GLIM criteria, patients were recorded for weight loss from phenotypic criteria based on information obtained from their relatives (more than five percent in the last six months or ten percent or more over the last six months). Hand dynamometer and calf circumference measurements were made to show muscle loss. Low Body Mass Index (BMI) was accepted as $20 \mathrm{~kg} / \mathrm{m}^{2}$ for individuals under the age of 70 years, and $<22$ for individuals above the age of 70 years. Decreased food intake which is among the etiologic criteria was detected by calculating the mean daily consumed calories of a patient. Individuals with $\mathrm{CRP}>5 \mathrm{mg} / \mathrm{L}$ were accepted as inflammation positive.

Results: Mean age in the total series was 72.98 with 70.4 in males and 75.5 in females including a total of 148 patients. Among the patients $50.67 \%(n=75)$ were males and $49.32 \%(n=73)$ were females. Malnutrition was found to be present in $141 / 148$ (94.6\%) patients according to the GLIM screening test. Malnutrition risk was present in 131/148 (87.9\%) and 139/148 (93.2\%) according to MNA-SF and NRS-2002, respectively. The results of the GLIM criteria and the other two screening tests were compared. While the results of the GLIM criteria and NRS-2002 test were similar, a significant difference was found between the GLIM test results and the results of MNA-SF.

Conclusion: The GLIM screening test is an easy-to-use and sensitive test for the diagnosis of patients hospitalized in palliative care centers. GLIM test and NRS- 2002 were found to be similar for diagnosing malnutrition. Although the results of MNA and GLIM tests were close, a significant difference was found between them in the diagnosis of malnutrition.
\end{abstract}

Keywords: Palliative care, malnutrition, nutrition assessment, elderly

\section{INTRODUCTION}

Malnutrition is a condition that is accompanied by weight loss as a result of the inability to consume sufficient nutrients and calories and is a serious health problem. The European Society for Clinical Nutrition and Metabolism (ESPEN) has defined malnutrition as inflammatory and disease-related or unrelated malnutrition as a basic concept of clinical nutrition. Excess weight and obesity are evaluated as separate concepts, not malnutrition (1). Malnutrition is a major cause of mortality and morbidity. It increases the duration of hospital stay and costs (2). Therefore, early diagnosis and the detection of patients at risk are important. There are many nutrition tests

available for the diagnosis of these patients. Some of them are easily applied and can be used for all patients. The validity and reliability of the commonly used tests, Nutritional Risk Screening (NRS)-2002 and Mini Nutritional Assessment (MNA) has been proven in the diagnosis and screening of malnutrition in hospitalized patients $(3,4)$.

A new malnutrition diagnostic criteria, called the Global Leadership Initiative on Malnutrition (GLIM), was created by an initiative of the same name to create a common test for the easy identification of the nutritional status of the medical community (5). These criteria were 
published in the ESPEN guidelines in September 2018 (5). Few studies have been published on the validity, reliability, and superiority of these criteria to other tests in palliative care centers. The present study aimed to evaluate the differences and superiority of one to another of the screening tests, MNA and NRS-2002 and GLIM criteria in a palliative care center with a high incidence of malnutrition. Our objective was to detect the degree of reliability and differences of these newly developed tests with other screening tests in diagnosing malnutrition in patients in palliative care centers.

\section{MATERIAL AND METHOD}

\section{Population and Setting:}

The study commenced following the decision of the Ethics Board of the University of Health Sciences, Erzurum Regional Training and Research Hospital (Date: 03.02.2020, Decision No: 37732058-514.10). All procedures were carried out in accordance with the ethical rules and the principles of the Declaration of Helsinki. Between February 2020 and December 2020, there were a total of 232 palliative hospitalizations for various reasons. Informed consent forms were obtained from all participating individuals. Nutritional tests with malnutrition (low daily calorie intake) over 18 years of age followed in palliative care were retrospectively analyzed and 148 of $232(63.7 \%)$ patients were included in the study. The study examined MNA, NRS-2002 and GLIM screening tests for each patient, which were filled by dietitians within the first 48 hours of the patient's admission to palliative care. Patients with a hospital stay of fewer than 48 hours and with missing data were excluded from the study. The reason for selecting the MNA-SF and NRS-2002 tests in the comparison of nutritional tests was based on the suggestion of evidence based guidelines (3).All three screening tests were applied in all patients.

\section{Measurements}

GLIM criteria consist of 5 criteria, including phenotypic and etiological criteria.

Phenotypic criteria: Weight loss=Within the framework of GLIM criteria, patients were recorded for weight loss from phenotypic criteria based on information obtained by self-reporting or from their relatives (more than five percent in the last six months or ten percent or more over the last six months).

Reduced muscle mass $=$ Hand dynamometer and calf circumference measurements were taken to show muscle loss. Handgrip power was measured three times in both hands using a Jamar Digital Hand Dynamometer and the highest value was recorded. Handgrip power cutoff value was accepted as $<22$ and $<32$ for women and men, respectively (6). Calf circumference was measured at the widest level between the knee and ankle while the patient was lying on his/her back. Individuals with a calf circumference of $<31 \mathrm{~cm}$ (the cut-off value) were considered to have muscle loss.

Low body mass index (BMI) was accepted as $20 \mathrm{~kg} / \mathrm{m}^{2}$ for individuals under the age of 70 years, and $<22$ for individuals above the age of 70 years.

Etiological criteria: Reduced food intake $=$ Calculations for the daily calorie intake of the patients were based on the food consumption cards that patients and relatives filled in. A decreased intake of food, as one of the etiologic criteria, was determined by calculating mean calories during the patients' hospital stay.

Inflammation $=\mathrm{C}$-reactive protein $(\mathrm{CRP})$, procalcitonin and prealbumin values were used for the detection of inflammation. Individuals with $\mathrm{CRP}>5 \mathrm{mg} / \mathrm{L}$ were accepted as inflammation positive. Also, any inflammatory diseases among the present diseases of the patients were determined.

Patients were diagnosed as having malnutrition when at least one point was given for phenotypical and etiologic criteria (5).

The MNA-SF screening test was applied. Patients with seven points or less (the total score is 14) were diagnosed as having malnutrition.

Patients with a $\geq 3$ (total points is six) in the NRS- 2002 test were diagnosed as having malnutrition. One point was added for patients over 70 years (7).

\section{Statistical Analysis}

All data entered into the database were verified by a second independent person. Descriptive statistics, as the mean and standard deviation for normally distributed continuous variables and relative frequencies for categorical (qualitative) variables, were generated for all variables. SPSS 22 Windows software (SPSS Inc, Chicago, Ill, USA) was used in the statistical analysis. If the $p$ value is $<0.05$, it indicates that there is a significant difference between groups

\section{RESULTS}

The study included 148 of 232 (63.7\%) malnutrition patients followed up at the palliative care center. Mean age was 72.98 years in the total series and 70.4 and 75.5 years in males and females, respectively. Among the patients $50.67 \%(\mathrm{n}=75)$ were males and $49.32 \%$ $(n=73)$ were females. Table 1 shows the demographic characteristics of the patients in detail. The mean duration of hospitalization in the palliative care center was found to be 46.49 days. The first three most 
common diseases among the diagnoses of the patients were terminal stage cancer, cerebrovascular diseases, and dementia in $36 \%(n=54), 24 \%(n=36)$ and $19 \%$ $(n=29)$, respectively. Table 2 presents the Laboratory values of the patients in detail. The mean calorie intake of the patients was calculated as $1273.07 \mathrm{kcal} /$ day and the men were found to have more daily calorie intake compared with the women. The mean CRP was calculated as 59.88. CRP was significantly higher in the group diagnosed as having malnutrition according to the GLIM criteria. The prealbumin level was found to be significantly lower in the group with malnutrition (Table 3) $(\mathrm{p}<0.05)$. Mean hand grip power was 8.2 $\mathrm{kg}$ and $4.2 \mathrm{~kg}$ in men and women, respectively. Calf circumference was measured as $27 \mathrm{~cm}$ and $29.94 \mathrm{~cm}$ in men and women, respectively. (Table 1). Malnutrition was found to be present in 141/148 (94.6\%) patients according to the GLIM screening test. Malnutrition risk was present in 131/148 (87.9\%) and 139/148 (93.2\%) according to MNA-SF and NRS-2002, respectively. The results of the GLIM criteria and the other two screening tests were compared. While the results of the GLIM criteria and NRS-2002 test were similar, a significant difference was found between the GLIM test results and the results of MNA-SF. The reason for the difference was considered to be the fact that more patients were diagnosed as having malnutrition when GLIM and NRS- 2002 tests were used, and the number was found to be smaller when MNA-SF was used (Table 4). Mean daily food consumption and the anthropometric measurements of the patients diagnosed to be normal according to MNA-SF were compatible.

\section{DISCUSSION}

In an extensive study carried out in Turkey, being at risk of malnutrition was found to be $28 \%$ (1). The rate of malnutrition among hospitalized patients was found to be $22 \%(8)$. However, in palliative care this rate escalated to $58.6 \%$ (9) and in our study $63.7 \%$ which is very high and was attributed to the high number of elderly cases with post-long-term intensive care hospitalization and with terminal stage cancer. The great majority of those patients were the ones who were hospitalized for a nutritional treatment in this clinic. These rates could increase up to $80-85 \%$ in patients with cancer and elderly cases in intensive care $(10,11)$. Patients with malnutrition or at a high risk of malnutrition, in particular, are hospitalized in palliative care clinics.

GLIM criteria is a newly developed nutrition screening test. This present study is among the first to be conducted in a palliative care center. Practical and easily applied nutrition tests are very important in palliative care centers where patients with malnutrition

\begin{tabular}{|c|c|c|c|}
\hline & Male & Female & mean \\
\hline Age, year & 70.4 & 75.51 & 72.99 \\
\hline Sex (male) & $50.67 \%(75)$ & $49.32 \%(73)$ & $100 \%(148)$ \\
\hline Height $(\mathrm{cm})$ & 171.4 & 154.6 & 163 \\
\hline Weight (kg) & 48.7 & 57.4 & 53.05 \\
\hline $\mathrm{BMI}, \mathrm{kg} / \mathrm{m}^{2}$ & 16.51 & 22.47 & 19.39 \\
\hline Handgrip (kg) & 8.2 & 4.2 & 6.2 \\
\hline Calf circumference & 27 & 29.94 & 28.47 \\
\hline Mean calories (daily, kcal) & 1345.47 & 1200.68 & 1273.07 \\
\hline $\begin{array}{l}\text { Percutaneous endoscopic } \\
\text { gastrostomy(PEG) }\end{array}$ & 17 & 12 & 29 \\
\hline Total Parenteral Nutrition & 19 & 21 & 41 \\
\hline
\end{tabular}

Table 2. Laboratory of patients

\begin{tabular}{|c|c|c|c|}
\hline Parameters & Mean & Min & $\max$ \\
\hline Glucose (mg/dl) & 128.32 & 51.00 & 482.00 \\
\hline Albumin (mg/dl) & 2.98 & 1.70 & 4.80 \\
\hline $\mathrm{BUN}(\mathrm{mg} / \mathrm{dl})$ & 25.15 & 6.00 & 125.00 \\
\hline Creatinine (mg/dl) & 0.87 & 0.32 & 4.66 \\
\hline Calcium (mg/dl) & 8.56 & 5.40 & 11.90 \\
\hline $\operatorname{ALT}(\mathrm{IU} / \mathrm{L})$ & 23.19 & 6.00 & 268.00 \\
\hline AST (IU/L) & 22.40 & 7.00 & 132.00 \\
\hline Protein (g/dl) & 5.90 & 3.64 & 8.77 \\
\hline Prealbumin (mg/dl) & 0.14 & 0.02 & 0.52 \\
\hline Procalcitonin (ng/mL) & 2.44 & 0.00 & 80.88 \\
\hline CRP (mg/L) & 59.89 & 3.10 & 456.00 \\
\hline WBC (cell/ $\mu \mathrm{L})$ & 9.44 & 2.57 & 30.85 \\
\hline Uric acid (mg/dl) & 4.56 & 1.30 & 20.40 \\
\hline FT4 (ng/dl) & 1.04 & 0.40 & 1.85 \\
\hline
\end{tabular}

Table 3. Malnutrition for GLIM criteria and laboratory difference

\begin{tabular}{|lcccccc|}
\hline \multirow{2}{*}{ Parameters } & \multicolumn{3}{c}{$\begin{array}{c}\text { Glim negative } \\
(\mathbf{n}=8)\end{array}$} & \multicolumn{3}{c}{$\begin{array}{c}\text { Glim positive } \\
(\mathbf{n}=140)\end{array}$} \\
\cline { 2 - 7 } & Mean & Min & Max & Mean & Min & Max \\
\hline $\begin{array}{l}{ }^{*} \text { Prealbumin } \\
(\mathrm{mg} / \mathrm{dl})\end{array}$ & 0.22 & 0.07 & 0.32 & 0.14 & 0.02 & 0.52 \\
${ }^{*} \mathrm{CRP}(\mathrm{mg} / \mathrm{L})$ & 27.95 & 3.1 & 103 & 61.71 & 3.1 & 456 \\
$\begin{array}{l}\text { Procalcitonin } \\
(\mathrm{ng} / \mathrm{mL})\end{array}$ & 0.15 & 0.01 & 0.48 & 2.57 & 0 & 80.88 \\
WBC $(\mathrm{cell} / \mu \mathrm{L})$ & 9.13 & 5.51 & 14.57 & 9.46 & 2.57 & 30.85 \\
Glucose $(\mathrm{mg} / \mathrm{dl})$ & 126.75 & 72 & 184 & 128.4 & 51 & 482 \\
$\begin{array}{l}\text { Albumin } \\
(\mathrm{mg} / \mathrm{dl})\end{array}$ & 3.29 & 2.6 & 4.1 & 2.95 & 1.7 & 4.8 \\
$\begin{array}{l}\text { Protein }(\mathrm{g} / \mathrm{dl}) \\
\text { TSH }\end{array}$ & 6.24 & 5.38 & 7.8 & 5.88 & 3.64 & 8.77 \\
\hline PSH & 2 & 0.16 & 6.02 & 2.59 & 0 & 69.08 \\
\hline
\end{tabular}

Parameters mean, median, min and $\max .{ }^{*} \mathrm{p}<0.05$

Laboratory differences between patients with and without malnutrition according to GLİM criteria

\section{Table 4. Malnutrition test GLIM vs MNA and NRS 2002}

\begin{tabular}{|lcccc|}
\hline \multirow{2}{*}{ GLIM } & \multicolumn{2}{c}{ MNA-SF } & \multicolumn{2}{c|}{ NRS 2002 } \\
\cline { 2 - 6 } & Negative & Positive & Negative & Positive \\
\hline Negative & 6 & 2 & 4 & 4 \\
Positive & 12 & 128 & 6 & 134 \\
& \multicolumn{2}{c}{$\mathrm{p}<0.05$} & \multicolumn{2}{c}{$\mathrm{p}>0.05$} \\
\hline
\end{tabular}


are most found. MNA-SF and NRS-2002 tests have a high sensitivity and specificity (12). MNA-SF effectively reflects social functions, presentation to the hospital, and mortality and morbidity, while NRS 2002 reflects the nutritional status of the inpatients depending on the severity of the disease $(7,13)$. Their validity and reliability have been proven; however, the development of a test is required that can be used universally, as one of the tests may be superior or another, according to the area of application (14). One or some of the tests may better detect the risk of mortality or rehospitalization (15). In a study by Matsumoto et al, similar to the present study, malnutrition was detected in $97.7 \%$ using the MNA-SF test and GLIM test (16). The GLIM criteria were developed for an easy-to-apply and universally used nutrition test. This present study aimed to compare the applicability and reliability of this test in palliative care patients.

\section{Limitation}

The limitations of this study were similar to those of other studies in which it is challenging to measure height, weight and loss of muscle mass in intensive care patients and patients with a poor general condition $(17,18)$ even though these measurements are among the parameters of total nutrition tests. Measuring height and weight was difficult in most of the patients as they were bedridden. The measurement of fat-free mass was performed using anthropometric measurements (19) as in this group of patients bia or DEXA would yield false results. Daily calorie consumption was based on the records of those accompanying the patients and this might have resulted in the record showing as deficient or excess consumption. Also, many of the patients were hospitalized before being admitted to palliative care and they also had weight loss in that period. Notably, many patients were hospitalized in the intensive care unit. Errors in the patients' measurements may have occurred due to edema or the patients being confined to bed.

\section{CONCLUSION}

The GLIM screening test is an easy-to-use and sensitive test in the diagnosis of patients hospitalized in palliative care centers. Both the GLIM test and NRS- 2002 were found to be similar in diagnosing malnutrition. Although the results of the MNA and GLIM tests were close, a significant difference was found between them in the diagnosis of malnutrition. We suggest that the NRS- 2002 or GLIM test is more practical and easier to use when screening for malnutrition in patients in palliative care centers. Future studies on the applicability and ease of these tests in different populations are required.

\section{ETHICAL DECLARATIONS}

Ethics Committee Approval: The study commenced following the decision of the Ethics Board of the University of Health Sciences, Erzurum Regional Training and Research Hospital (Date: 03.02.2020, Decision No: 37732058-514.10).

Informed Consent: Because the study was designed retrospectively, no written informed consent form was obtained from patients.

Referee Evaluation Process: Externally peer-reviewed.

Conflict of Interest Statement: The author(s) declared no potential conflicts of interest with respect to the research, authorship, and/or publication of this article.

Financial Disclosure: The authors have not declared a specific grant for this research from any funding agency in the public, commercial or not-for-profit sectors.

Author Contributions: All of the authors declare that they have all participated in the design, execution, and analysis of the paper, and that they have approved the final version.

\section{REFERENCES}

1. Cederholm T, Barazzoni R, Austin P, et al. ESPEN guidelines on definitions and terminology of clinical nutrition. Clin Nutr 2016; 36: 49-64.

2. Lew CCH, Yandell R, Fraser RJL, Chua AP, Chong MFF, Miller M. Association between Malnutrition and Clinical Outcomes in the Intensive Care Unit: A Systematic Review. J Parenter Enter Nutr 2017; 41: 744-58.

3. Board P. Dietetics \& Nutrition 2019; 6368: 1-24.

4. Bolayir B, Arik G, Yeşil Y, et al. Validation of Nutritional Risk Screening-2002 in a hospitalized adult pPopulation. Nutr Clin Pract 2019; 34: 297-303.

5. Compher C, Fuchs-Tarlovsky V, Siltharm S, et al. GLIM criteria for the diagnosis of malnutrition - A consensus report from the global clinical nutrition community. Clin Nutr 2019; 38: 1-9.

6. Bahat G, Tufan A, Tufan F, et al. Cut-off points to identify sarcopenia according to European Working Group on Sarcopenia in Older People (EWGSOP) definition. Clin Nutr 2016; 35: 1557 63.

7. Kondrup J, Allison SP, Elia M, Vellas B, Plauth M. ESPEN guidelines for nutrition screening 2002. Clin Nutr 2003; 22: 41521.

8. Ülger Z, Halil M, Kalan I, et al. Comprehensive assessment of malnutrition risk and related factors in a large group of community-dwelling older adults. Clin Nutr 2010; 29: 507-11.

9. Yürüyen M, Özbaş Tevetoğlu I, Tekmen Y, Polat Ö, Arslan İ, Okuturlar Y. Prognostic Factors and Clinical Features in Palliative Care Patients. Konuralp Tip Derg 2018; 10: 74-80.

10. Muscaritoli M, Lucia S, Farcomeni A, et al. Prevalence of malnutrition in patients at first medical oncology visit: the PreMiO study. Oncotarget 2017; 8: 79884-96.

11.Shpata V, Ohri I, Nurka T, Prendushi X. The prevalence and consequences of malnutrition risk in elderly Albanian intensive care unit patients. Clin Interv Aging 2015; 10: 481-6. 
12. Young AM, Kidston S, Banks MD, Mudge AM, Isenring EA. Malnutrition screening tools: Comparison against two validated nutrition assessment methods in older medical inpatients. Nutrition 2013; 29: 101-6.

13. Kaiser MJ, Bauer JM, Ramsch C, et al. Validation of the Mini Nutritional Assessment short-form (MNA $\left.{ }^{\circ}-\mathrm{SF}\right)$ : A practical tool for identification of nutritional status. J Nutr Heal Aging 2009; 13: $782-8$

14. Christner S, Ritt M, Volkert D, Wirth R, Sieber CC, Gaßmann KG. Evaluation of the nutritional status of older hospitalized geriatric patients: a comparative analysis of a Mini Nutritional Assessment (MNA) version and the Nutritional Risk Screening (NRS 2002). J Hum Nutr Diet 2016; 29: 704-13.

15. Koren-Hakim T, Weiss A, Hershkovitz A, et al. Comparing the adequacy of the MNA-SF, NRS-2002 and MUST nutritional tools in assessing malnutrition in hip fracture operated elderly patients. Clin Nutr 2016; 35: 1053-8.

16. Matsumoto Y, Iwai K, Namikawa N, et al. The relationship between existing nutritional indicators and Global Leadership Initiative on Malnutrition (GLIM) criteria: A one-institution cross-sectional analysis. Clin Nutr 2020: 1-6.

17.Freitag E, Edgecombe G, Baldwin I, Cottier B, Heland M. Determination of body weight and height measurement for critically ill patients admitted to the intensive care unit: A quality improvement project. Aust Crit Care 2010; 23: 197-207.

18. Bloomfield R, Steel E, MacLennan G, Noble DW. Accuracy of weight and height estimation in an intensive care unit: Implications for clinical practice and research. Crit Care Med 2006; 34: 2153-7.

19. Hull HR, Thornton J, Wang J, et al. Fat-free mass index: Changes and race/ethnic differences in adulthood. Int J Obes 2011; 35: $121-7$. 